\title{
Eco-friendly green synthesis of silver nanoparticles using salmalia malabarica: synthesis, characterization, antimicrobial, and catalytic activity studies
}

\author{
I. Murali Krishna ${ }^{1}$ G. Bhagavanth $\operatorname{Reddy}^{1}$ - G. Veerabhadram ${ }^{1}$. \\ A. Madhusudhan ${ }^{1}$
}

Received: 16 April 2015/Accepted: 27 June 2015/Published online: 15 July 2015

(C) The Author(s) 2015. This article is published with open access at Springerlink.com

\begin{abstract}
An economically viable and "green" process has been developed for the synthesis of silver nanoparticles (AgNPs) with an average size of $7 \mathrm{~nm}$ using non-toxic and renewable salmalia malabarica gum (SMG) as reducing and capping agent without using any chemical reducing agent. The effect of various parameters such as concentration of SMG and silver nitrate and reaction time for the synthesis of AgNPs was studied. The synthesized AgNPs are systematically characterized by UV/Vis spectroscopy, Fourier transform infrared spectroscopy, X-ray diffraction and Transmission electron microscopy. The resultant SMG-capped AgNPs are highly stable and had significant antibacterial action on both Escherichia coli (E. coli) and Staphylococcus aureus (S. aureus). The catalytic action of the SMG-capped AgNPs to initiate the reduction of 4-nitrophenol (4-NP) in the presence of $\mathrm{NaBH}_{4}$ has also been reported. The kinetics of the reaction was found to be of pseudo-first-order with respect to the 4-NP.
\end{abstract}

Keywords Salmalia malabarica gum $(\mathrm{SMG}) \cdot$ Silver nanoparticles (AgNPs) · Microbial activity · Catalysis · Pseudo-first-order reaction

\footnotetext{
A. Madhusudhan

allemadhusudhan@gmail.com

G. Veerabhadram

gvbhadram@gmail.com

1 Department of Chemistry, University College of Science, Osmania University, Hyderabad 500007, Telangana State, India
}

\section{Introduction}

Nowadays much attention has been focused on metal nanoparticles such as silver, gold, platinum, and copper as their properties may significantly differ from their respective bulk metals (Burda et al. 2005). These metal nanoparticles exhibit size-dependent optical and electronic properties. Among several nanomaterials of recent interest, the most prominent one is that of silver (AgNPs) due to its unique size and shape-dependent optical, electronic, and catalytic properties (El-Sayed 2001; Tang et al. 2010; Chau and Yeh 2011). Silver makes it an excellent choice for numerous roles in the medical field for antifungal, antioxidant, and anti-inflammatory effects (Kenneth et al. 2009; Sang et al. 2012; Amit Kumar et al. 2012). Nanosilver belongs to a class of highly commercialized nanomaterials due to its strong antimicrobial activity (Chen and Schluesener 2008). Nanosilver and its compounds are well established, and have wide antibacterial spectrum (Mahapatra and karak 2008; Tiwari et al. 2008). Owing to their strong antimicrobial properties, AgNPs find a plethora of applications such as nanosilver coated ceramic water filters, activated carbon air filters, wound dressings (Maneerung et al. 2008; Sharma et al. 2009), catheters, biodegradable poly(L-lactide) (PLA) fibers (Xu et al. 2006), cosmetics, antibacterial sprays, and children's toys (Jones and Hoek 2010).

The synthesis of AgNPs generally involves three welldefined methods. The first method involves the use of strong reducing agents, such as hydrazine (Jana and Peng 2003) and borohydride ions (Shon and Cutler 2004). The second physical method involves radiation techniques such as ultrasound irradiation, $\gamma$-radiation, and microwave irradiation (Jiang et al. 2004; Yoksan and Chirachanchai 2009; Pal et al. 2009). The third method involves prolonged 
heating of silver ions in solution in presence of weak reducing agents such as ascorbic acid, sodium citrate, and glucose (Lee et al. 2004; Yin et al. 2004; Yu and Yam 2004). Most of these methods involve the utilization of harsh reducing agents, capping agents, and organic solvents (Jana and Peng 2003; Qu et al. 2006; Roldan et al. 2008), which are carcinogenic, and these factors should be considered expensive from an economic and "green" chemistry perspective. Therefore, it is necessary to develop environmentally sustainable processes, involving green chemistry principles, for the preparation of silver nanoparticles using biocompatible reducing agents. These can act as capping and stabilizing agents for the synthesis of silver nanoparticles. The synthesis was carried out in aqueous medium by autoclaving without the requirement of any added chemical reducing agents. In this study, autoclaving method (thermal treatment) was adopted as a pseudo-synthetic route to produce sterile silver nanoparticles that are completely free from viruses, bacteria, and spores, and these sterile silver nanoparticles may find biological applications. Earlier studies report the use of plant leaf extracts, seed extracts, naturally occurring gums, and living organisms for green synthesis of AgNPs (ElRafie et al. 2010; Lori Rastogi and Arunachalam 2011).

Salmalia malabarica gum (SMG) is a naturally occurring plant polysaccharide gum obtained from the plant Bombax ceiba, a native tree of India. It is easily available, costeffective, non-toxic, eco-friendly, biodegradable, and renewable polysaccharide material. This gum is used in traditional ayurvedic and unani medical preparations for treatment of anti-inflammatory, analgesic, hepato-protective, hypotensive, anticancer, asthma, diarrhea, wound healing, antioxidant, and hypoglycemic activity (Saleem et al. 2003; Faizi et al. 2012; Jain and Verma 2012). Hence, the synthesis of AgNPs using SMG is cost-effective and has many biomedical advantages. SMG is a negatively charged colloid and a high molecular weight polysaccharide complex. The complete hydrolysis of the gum has revealed that it contains a mixture of various sugars such as D-galacturonic acid, 2,3,4,6-tetra- $O$-methyl-D-galactose, 2,6-di- $O$-methyl-D-galactose, 2,4-di- $O$-methyl-D-galactose, 2,3,5-tri- $O$-methyl-L-arabinose, 2,5-di- $O$-methyl-L-arabinose, and $\alpha$-norneolignan (Bose and Dutta 1963a, b). Green synthesis of AgNPs has been carried out using a variety of polysaccharides, including gum kondagogu, xanthan gum, gellan gum, locust bean gum (Aruna Jyothi et al. 2010; Dhar et al. 2012; Tagad et al. 2013; Wei et al. 2014), etc. But, green synthesis of AgNPs using salmalia malabarica gum (silk cotton) as a reducing and capping agent has not been reported yet.

In the present study, AgNPs have been synthesized by reduction of silver nitrate salt using SMG, which acts as both a reducing and capping agent, and water as a solvent.
A simple mixing of SMG with silver nitrate results in synthesis of AgNPs in less than $12 \mathrm{~h}$, however, the concentration of AgNPs is low because without autoclaving, gum expansion is poor, resulting in less interaction of silver ions with the available functional groups on the gum. Its natural abundance in this geographical area, non-toxicity, and multifunctional nature has prompted us to select this gum for the present study. The main focus in this study is synthesis, characterization, and antimicrobial activity of SMG-capped AgNPs. Antimicrobial activity tests were conducted on bacterial strains of E. coli and S. aureus to evaluate the efficacy of the generated nanoparticles for their potential biomedical applications. Catalytic activity of SMG-capped AgNPs towards 4-nitrophenol (4-NP) reduction has also been reported. The SMG-capped AgNPs catalyst exhibited very a good catalytic activity and the kinetics of the reaction was found to be of pseudo-firstorder with respect to 4-NP.

\section{Experimental}

\section{Materials}

Salmalia malabarica gum was purchased from Girijan Cooperative Corporation, Andhra Pradesh, India. Silver nitrate, 4-nitrophenol, and sodium borohydride, all are of AR Grade, were obtained from Merck Limited, Mumbai, India. The test strains, E. coli (MTCC 1303) and S. aureus (ATCC 25923) were purchased from IMTECH, Chandigarh, India. Yeast extract, tryptophan, and bacterial grade agar-agar were purchased from HiMedia Laboratories, Mumbai, India.

\section{Preparation of silver nanoparticles}

Glassware was cleaned in a bath of freshly prepared aquaregia solution $\left(\mathrm{HCl}: \mathrm{HNO}_{3} 3: 1\right)$ and then rinsed thoroughly with distilled water prior to use. Uniform AgNPs can be obtained by the reduction of silver nitrate $\left(\mathrm{AgNO}_{3}\right)$ using SMG by autoclaving method (Osworld, Model No. OAT G-37, Mumbai, India) at 15 psi pressure and $120{ }^{\circ} \mathrm{C}$ temperature. In this synthesis process, $5 \mathrm{~mL}$ of aqueous solution containing silver nitrate $\left(0.5 \mathrm{~g}\right.$ of $\left.\mathrm{AgNO}_{3}\right)$ and $5 \mathrm{~mL}$ of aqueous solution containing SMG ( $0.5 \mathrm{~g}$ of SMG), were taken into boiling tube. The boiling tube was sealed with aluminum foil and kept in autoclave. A series of AgNPs were prepared by varying the time of autoclaving, concentrations of $\mathrm{AgNO}_{3}$ and SMG at 15 psi pressure and $120{ }^{\circ} \mathrm{C}$ temperature. The colorless reaction mixture was converted to the characteristic clear yellow color after autoclaving which indicates the formation of silver nanoparticles. 


\section{Characterizations of silver nanoparticles}

The analysis of SMG-capped AgNPs solution was carried out on a Dual Beam UV-visible spectrophotometer (Shimadzu-3600, Japan). Fourier transform infrared (FTIR) spectra of SMG alone and SMG-capped AgNPs were recorded in $\mathrm{KBr}$ pellets using an FTIR spectrophotometer (Bruker Optics-TENSOR 27, Germany). The scan was performed in the wavenumber range of $400-4000 \mathrm{~cm}^{-1}$. X-ray diffraction (XRD) measurements of SMG-capped AgNPs were carried out on X'pert Pro MRD X-ray diffractometer (PANalytical BV, The Netherlands) operating at $40 \mathrm{kV}$ and a current of $30 \mathrm{~mA}$ at a scan rate of $0.388 \mathrm{~min}^{-1}$. The morphology and size distribution measurements of the SMG-capped AgNPs were carried out by TECHNAI $G^{2}$ F30 S-TWIN transmission electron microscope (TEM) (FEI Company, USA) operated at an accelerating voltage of $200 \mathrm{kV}$, casting nanoparticle dispersion on carbon-coated copper grids and allowing for drying at room temperature.

\section{Antibacterial property of samples}

The disc diffusion method was used to study the antibacterial activity of the eco-friendly synthesized AgNPs. Luria-Bertani (LB) agar medium was prepared by adding yeast extract $(0.5 \mathrm{~g})$, tryptophan $(1 \mathrm{~g})$, sodium chloride $(1 \mathrm{~g})$, and bacterial grade agar $(2.5 \mathrm{~g})$ in distilled water $(100 \mathrm{~mL})$. The prepared agar medium was then sterilized by autoclaving at a pressure of $15 \mathrm{psi}$ and $120^{\circ} \mathrm{C}$ temperature for $30 \mathrm{~min}$. This medium was transferred to sterilized Petri dishes in a laminar airflow. After solidification of media, overnight cultures of E. coli $(100 \mu \mathrm{L})$, and $S$. aureus $(100 \mu \mathrm{L})$ were spread separately over the surface of the agar media. Sterile discs were kept on these inoculated plates with the help of sterile forceps. Sample $(10 \mu \mathrm{L})$ solutions were placed on these discs, and incubated at $37^{\circ} \mathrm{C}$ for $24 \mathrm{~h}$ in a bacterial incubator. The zone of inhibition (ZOI) that appeared around the disc was measured and recorded as the antibacterial effect of SMG-capped AgNPs. Ampicillin was used as a positive control in the experiment.

\section{Catalytic activity}

The catalytic reduction of 4-nitrophenol (4-NP) was carried out in a standard quartz cuvette of about $3 \mathrm{~mL}$ volume. The reaction procedure was as follows: initially freshly prepared $1 \mathrm{~mL}$ of $15 \mathrm{mM} \mathrm{NaBH}_{4}$ solution was mixed with $1.7 \mathrm{~mL}$ of $0.2 \mathrm{mM} 4-\mathrm{NP}$ solution in the quartz cuvette. At this stage, the change of color from light yellow to yellowgreen was observed. Immediately after addition of $10 \mu \mathrm{L}$ volume of SMG-capped AgNPs to the above solution, the absorption spectra were recorded on UV-visible spectrophotometer with a time interval of $5 \mathrm{~min}$ and a wavelength range between 200 and $600 \mathrm{~nm}$ at $25^{\circ} \mathrm{C}$ temperature. The rate constant of the redox reaction was dependent on the change in absorbance at $400 \mathrm{~nm}$ as a function of time.

\section{Results and discussion}

Green synthesis of AgNPs was carried out using SMG as both capping and reducing agent, and water as solvent. This reaction was carried out in autoclave at 15 psi pressure and $120{ }^{\circ} \mathrm{C}$ temperature. During autoclaving under the influence of temperature and pressure, SMG gum expands and becomes more accessible for the silver ions to interact with the available functional groups on the gum. Autoclave (thermal treatment) was adopted as a pseudo-synthetic route to produce sterile silver nanoparticles that are completely free from viruses, bacteria, and spores and these sterile silver nanoparticles may find many biological applications.

\section{UV-visible spectroscopy analysis}

The prepared AgNPs were characterized by UV-visible spectroscopy. UV-visible spectroscopy is one of the most widely used and valuable technique for the observation of NPs synthesis. The synthesized AgNPs displayed the characteristic surface plasmon resonance (SPR) band in the spectral range of $418-428 \mathrm{~nm}$ (Kora et al. 2009). To optimize the nanoparticles synthesis, the influences of different parameters such as concentration of $\mathrm{AgNO}_{3}$, concentration of SMG, and autoclave time were studied. The UV-visible spectra of AgNPs, prepared by reducing different concentrations of $\mathrm{AgNO}_{3}$ with $0.5 \%$ SMG for $15 \mathrm{~min}$ of autoclaving at $15 \mathrm{psi}$ pressure and $120^{\circ} \mathrm{C}$ temperature, are shown in Fig. 1a. The efficacy of formation of AgNPs increased with the increase in the concentration of $\mathrm{AgNO}_{3}$ due to the increment in the oxidation of $-\mathrm{OH}$ groups by silver ions. This may be attributed to the formation of more AgNPs as the reaction progresses since the intensity of the surface plasmon peak is directly proportional to the density of the AgNPs in solution. Further, the production of nanoparticles with $0.5 \% \mathrm{AgNO}_{3}$ was monitored with varying concentrations of SMG $(0.1-0.5 \%)$ for 15 min of reaction time and the respective spectra are represented in Fig. 1b. It was noticed that the efficacy of nanoparticle synthesis increased with increase in the concentration of gum. Also, the effect of autoclave time (5-15 min) at 15 psi pressure and $120{ }^{\circ} \mathrm{C}$ temperature was studied with gum and $\mathrm{AgNO}_{3}$ concentrations at $0.5 \%$ and the respective spectra are shown in Fig. 1c. It was observed 

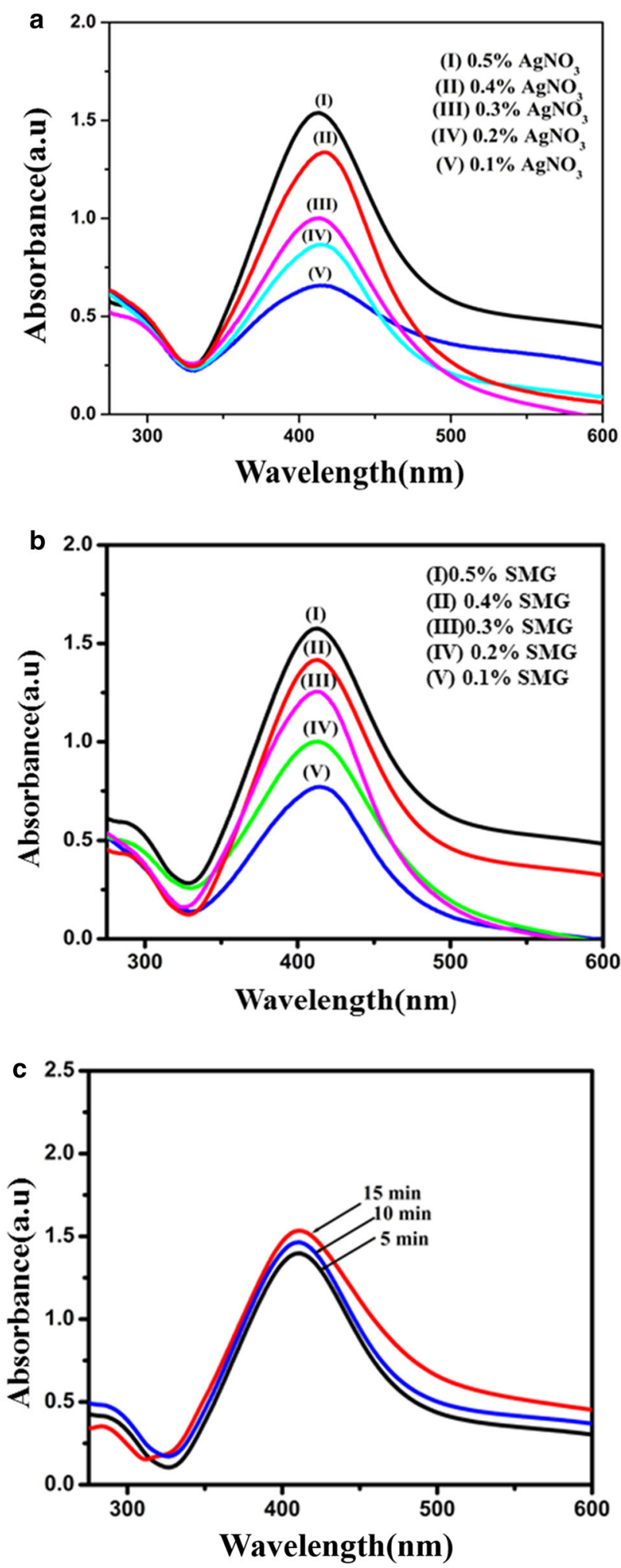

Fig. 1 UV-visible spectra of SMG-capped AgNPs synthesized by a using various concentrations of silver nitrate $(0.1-0.5 \%)$ at $0.5 \%$ SMG and $15 \mathrm{~min}$ of autoclaving time. b Various concentrations of SMG $(0.1-0.5 \%)$ at $0.5 \%$ silver nitrate and $15 \mathrm{~min}$ of autoclaving time. c Varying the reaction time from 5 to $15 \mathrm{~min}$ with SMG and $\mathrm{AgNO}_{3}$ concentrations of $0.5 \%$ that the formation of AgNPs steadily increased with an increase in the reaction time. The results suggest that the reduction capacity of the gum increased with reaction time. As the autoclaving time increases, possibly more and more of hydroxyl groups are being converted to carbonyl groups by air oxidation, which in turn reduce the silver ions.

\section{XRD analysis of AgNPs}

The XRD technique was used to determine and ascertain the crystal structure of eco-friendly synthesized stable AgNPs. Figure 2 clearly shows four well-defined characteristic peaks at scattering angles $(2 \theta)$ of $38.19,45.27$, 64.26, 77.28 corresponding to the (111), (200), (220), and (311) sets of lattice planes which may be indexed as the band for face-centered cubic (fcc) crystal structure of AgNPs. The peak corresponding to the (111) is more intense than the other planes. The broadening of these peaks is mostly due to the effect of nano-sized particles. The width of the (111) peak was employed to calculate the average nanoparticles size using the Scherrer formula with an applied geometric factor of 0.97 . It was found that the calculated average particle size was about $8.04 \mathrm{~nm}$ and the same was in agreement with the obtained TEM image.

\section{FTIR analysis of AgNPs}

Fourier transform infrared spectra of SMG and SMG-capped nanoparticles were recorded to provide an evidence for the interaction of functional groups of gum involved in the reduction of $\mathrm{Ag} \mathrm{NO}$ and the capping of subsequently formed AgNPs. The FTIR spectra of SMG (cure A) and SMG-capped AgNPs (cure B) are shown in Fig. 3. The FTIR spectra of SMG exhibited characteristic stretching frequencies at 3431, 2924, 1606, 1450, 1325, 1114, and $1026 \mathrm{~cm}^{-1}$, while the SMG-capped AgNPs showed characteristic stretching frequencies at 3483, 2940, 1648, 1473, 1356,1125 , and $1099 \mathrm{~cm}^{-1}$. The bands observed at 3483 ,

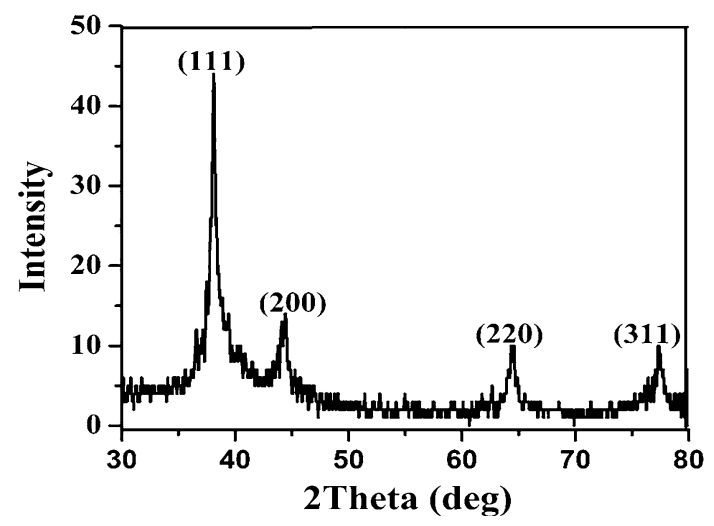

Fig. 2 Typical XRD pattern of the SMG-capped AgNPs 


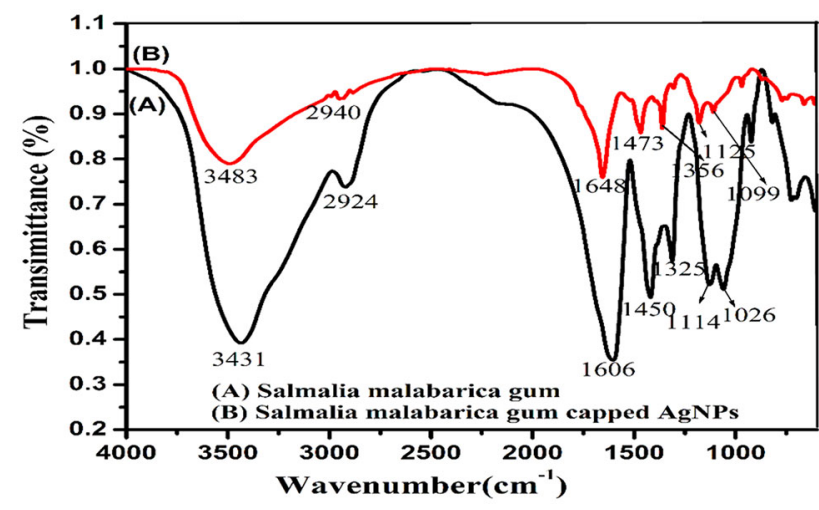

Fig. 3 FTIR Spectra of SMG-capped AgNPs and pure SMG

2940, 1648, and $1473 \mathrm{~cm}^{-1}$ suggest the $-\mathrm{OH}$ group, asymmetric $\mathrm{C}-\mathrm{H}$ stretch, carbonyl stretching vibration, and symmetrical stretch of carboxylate group, respectively. Also, the bands observed at 1356, 1125, and $1099 \mathrm{~cm}^{-1}$ represent the presence of acetyl functional group, $\mathrm{C}-\mathrm{O}$ stretching vibration of ether and alcohol functional groups, respectively. A shift in the peaks of the FTIR spectrum of SMG-capped AgNPs was observed from 3431 to $3483 \mathrm{~cm}^{-1}$ and 1606 to $1648 \mathrm{~cm}^{-1}$ and the remaining peaks are almost unchanged, suggesting the binding of AgNPs with hydroxyl and carboxyl groups. This can be attributed to the contribution both hydroxyl and carbonyl functional groups of gum in the preparation and stabilization of AgNPs.

\section{TEM analysis}

Typical TEM images of eco-friendly synthesized SMGcapped AgNPs using $0.5 \%$ silver nitrate and $0.5 \%$, SMG autoclaved for $15 \mathrm{~min}$ are shown in Fig. 4a. It was evident from the TEM images that the SMG-capped AgNPs were spherical in shape, and were well distributed in the gum polymer matrix. To get data on particle size distribution of AgNPs, approximately 179 particles were counted and then plotted into histograms. Histogram of the particle size distribution of AgNPs (Fig. 4b) depicts that the average particle size of AgNPs is about $7 \pm 2 \mathrm{~nm}$. The selected area electron diffraction (SAED) pattern (Fig. 4c) exhibits polycrystalline diffraction rings, indicating that these nanoparticles are highly crystalline in nature. These rings can be attributed to the diffractions from the (111), (200), (220), and (311) planes of cubic-phase metallic silver. When the concentration of SMG decreases from 0.5 to $0.1 \%$, the particle size of the AgNPs formed increased as shown in Fig. 4d. This increase in particle size, as gum concentration decreases, is due to the interaction between ionic silver and functional group on SMG as well as less effective the rate of nanoparticle capping. At higher concentration of SMG, the aggregation was slighter due to minor collision of AgNPs. Consequently, nanoparticles with monodispersity were obtained with $0.5 \%$ SMG and $15 \mathrm{~min}$ of autoclave time at $0.5 \%$ of $\mathrm{AgNO}_{3}$ concentration.

\section{Stability of AgNPs against pH and $\mathrm{NaCl}$}

The eco-friendly synthesized, SMG-capped AgNPs were studied for their stability under different $\mathrm{pH}$ and electrolytic conditions. The effect of $\mathrm{pH}$ on SPR peak was studied by varying pH 2-9 (Fig. 5a). Variation of pH did not affect the stability of SMG-capped AgNPs; there is no shift in the SPR peak and the peak intensity was decreased due to dilution. In the second scenario, the influence of salt effect on the stability of the AgNPs is shown in Fig. 5b. The synthesized AgNPs exhibited very high stability on the addition of varying concentrations (1-5 M) of sodium chloride $(\mathrm{NaCl})$. This is attributed to the fact that the resultant AgNPs were found to be quite stable even in the presence of $\mathrm{NaCl}$, owing to the protection of $\mathrm{SMG}$ on the nanoparticle surface.

\section{Microbial activity}

In the present study, the antibacterial activities of SMGcapped AgNPs and SMG alone were tested by disc diffusion method using both E. coli and S. aureus (Fig. 6) and the ZOI values for the above mentioned samples were recorded. The ZOI appeared around the disc was construed as a measure of the antibacterial effectiveness of SMGcapped AgNPs and SMG alone. The diameter of the ZOI of about $18 \mathrm{~mm}$ was observed for $5 \mathrm{mg} \mathrm{mL}^{-1}$ of SMG-capped AgNPs, where as that of $16 \mathrm{~mm}$ was observed for $1 \mathrm{mg} \mathrm{mL}^{-1}$ SMG-capped AgNPs for both E. coli and $S$. aureus. The negative control, i.e., autoclaved pure SMG sample showed no inhibition ability. Based on the results, it was evident that the ZOI decreases with the decrease in concentration of AgNPs (Fig. 6) which shows the antibacterial effectiveness of AgNPs. It can also be concluded from the results that the synthesized AgNPs had significant antibacterial activity against both the Grampositive and Gram-negative bacteria i.e., S. aureus and E. coli, respectively. This observation is in excellent agreement with earlier studies (Cho et al. 2005; Xu et al. 2006, 2009; Sharma et al. 2009). The mechanism of the bactericidal activities of silver (0) and AgNPs remains to be understood. Several studies suggest that silver tends to have a greater affinity to react with phosphorus and sulfur compounds (Ahrland et al. 1958; Hatchett and Henry 1996). The cell wall of the bacteria, as is well known, contains many sulfur-containing proteins and these might be preferential sites for the AgNPs to act. On the other 
Fig. 4 Particle size and morphology of eco-friendly synthesized AgNPs. a TEM image of AgNPs synthesized with $0.5 \%$ SMG and $0.5 \%$ $\mathrm{AgNO}_{3}$, autoclaved for $15 \mathrm{~min}$, b histogram showing the particle size distribution of AgNPs, $\mathbf{c}$ corresponding SAED pattern of AgNPs. d TEM image of AgNPs synthesized with $0.1 \% \mathrm{SMG}$ and $0.5 \% \mathrm{AgNO}_{3}$, autoclaved for $15 \mathrm{~min}$
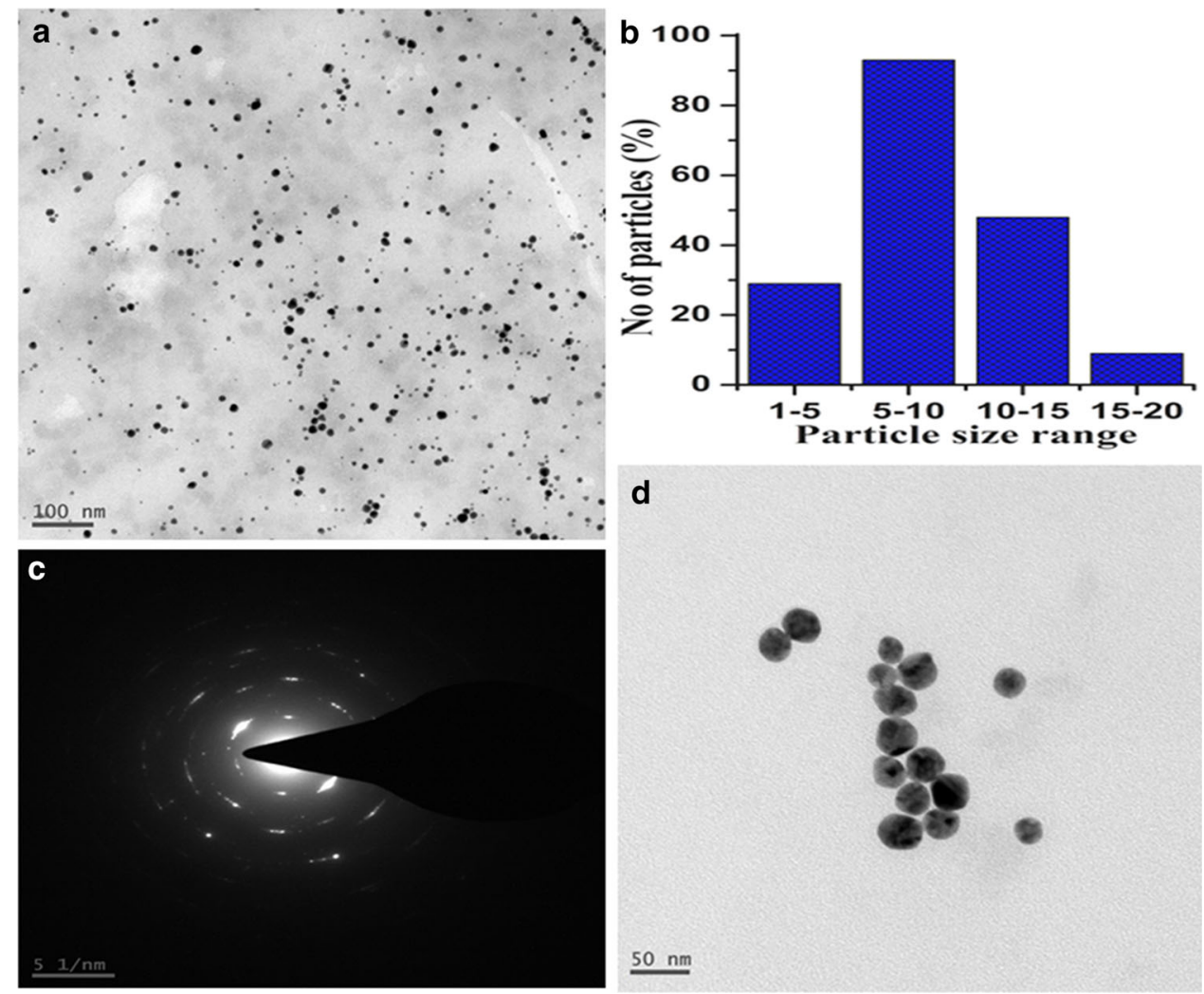
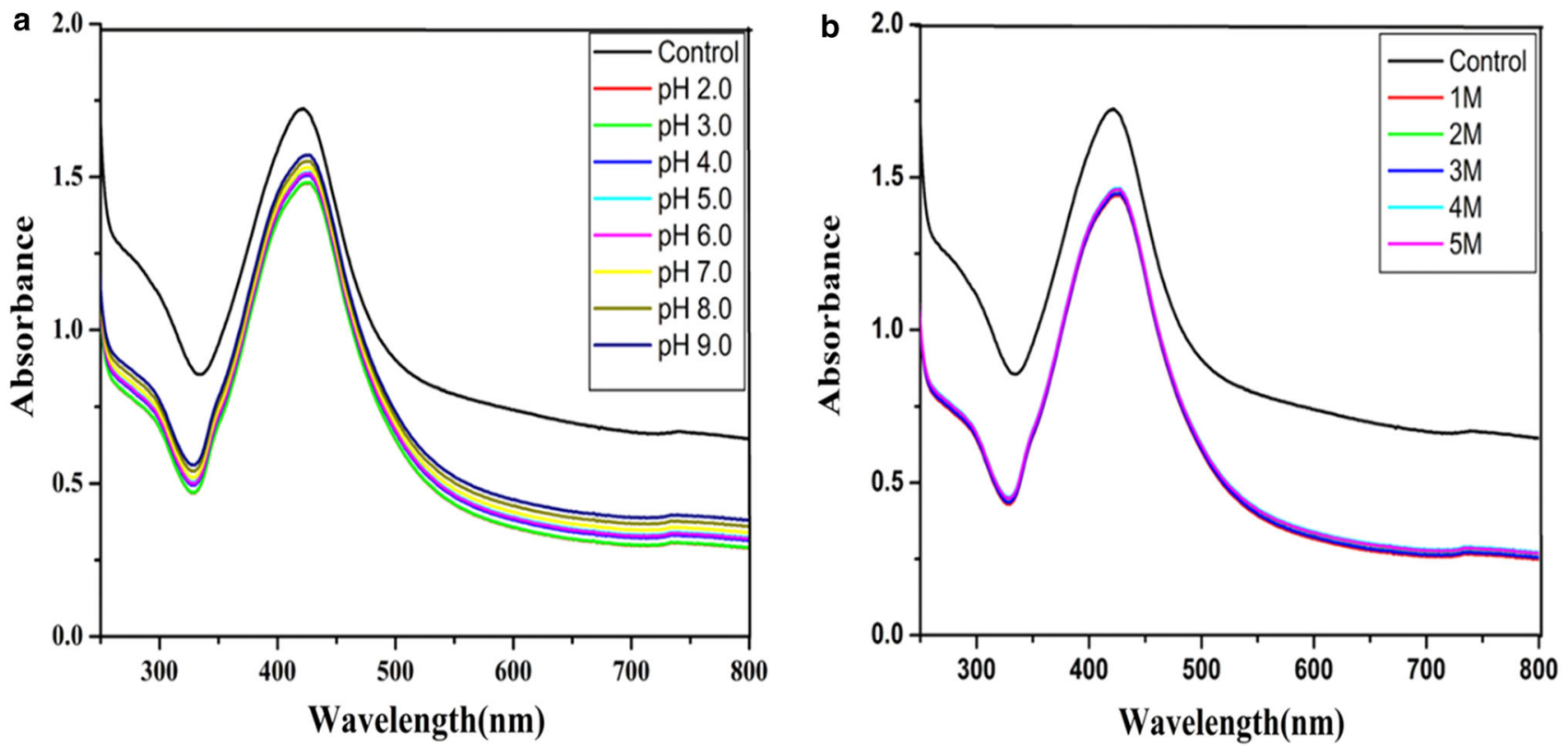

Fig. 5 Effect of pH (a) and salt concentration (b) on the stability of SMG-capped AgNPs

hand, AgNPs of size 1-60 nm effectively react with sulfurcontaining proteins inside the cell, as well as phosphoruscontaining compounds such as DNA in the cell nucleus (Prabhu and Poulose 2012). In addition, it is also believed that after penetration into the bacterial cell, AgNPs inactivate bacterial enzymes essential for their metabolic activity, generating hydrogen peroxide, and causing bacterial cell to death (Stockman and Barrett 1983; Raffi et al. 


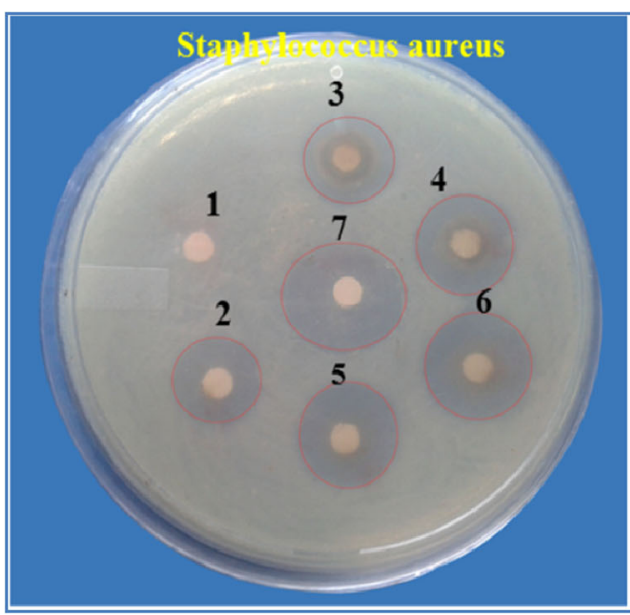

Fig. 6 Antibacterial test results of AgNPs with S. aureus and E.coli after $24 \mathrm{~h}$ of incubation. As concentration of $\mathrm{AgNO}_{3}$ decreases the $\mathrm{ZOI}$ also decreases. The concentration of $\mathrm{AgNO}_{3}$ per $1 \mathrm{~mL}$ of SMG, used for synthesis of AgNPs (1) pure gum SMG, (2) $5 \mathrm{mg} \mathrm{mL}^{-1}$

2008). It is also concluded that the detrimental reactions of AgNPs with DNA chain lead the latter to lose of its ability to replicate any further and cellular proteins become inactivated on silver ion treatment (Kumar et al. 2008). Higher concentrations of $\mathrm{Ag}^{+}$ions have been shown to interact with cytoplasmic components and nucleic acids (Feng et al. 2000) and affect the bacteria in their metabolic processes such as the cell respiration and cell division, finally causing the death of the cell.

\section{Catalytic function of AgNPs}

The most important application of metallic nanoparticles is the ability to catalyze some reactions that are, otherwise, difficult to occur. To verify the catalytic reduction of 4-NP to 4-aminophenol (4-AP) by $\mathrm{NaBH}_{4}$, SMG-capped AgNPs, as catalyst, was studied. The maximum absorbance $\left(\lambda_{\max }\right)$ of aqueous 4-NP at $317 \mathrm{~nm}$ was shifted to $400 \mathrm{~nm}$ right after addition of $\mathrm{NaBH}_{4}$ due to the generation of yellow-green colored nitrophenolate ions in the solution (Devi and Mandal 2013). The peak at $400 \mathrm{~nm}$ remained unaltered for quite a longer duration in the absence of AgNPs catalyst, indicating that $\mathrm{NaBH}_{4}$ itself does not act as strong reducing agent in the conversion of 4-NP to 4-AP. Interestingly, the addition of aliquot of SMG-capped AgNPs to the reaction mixture resulted in the gradual decrease in the height of the peak at $400 \mathrm{~nm}$, due to gradual disappearance of the 4-NP, with concurrent appearance of peak at $300 \mathrm{~nm}$ corresponding to the formation of 4-aminophenol (4-AP) was observed. Increasing peak at $300 \mathrm{~nm}$ and decreasing peak at $400 \mathrm{~nm}$ were quantitatively monitored using UV-visible spectroscopy as a function of time (Fig. 7). This suggests that the

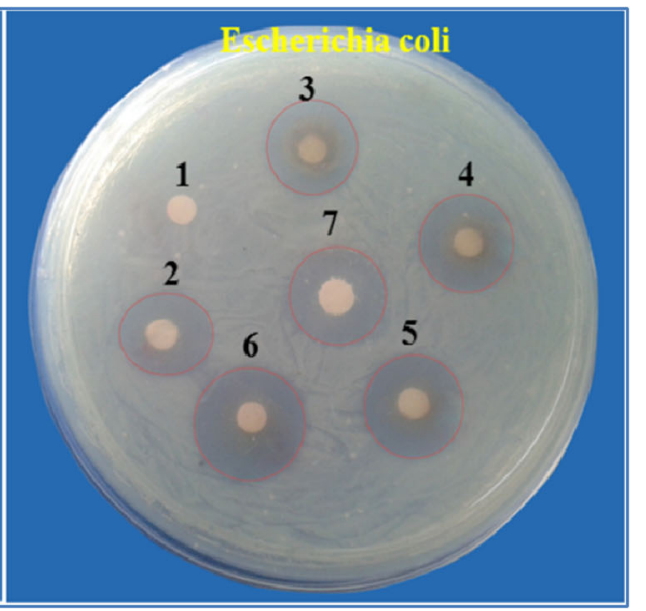

$\mathrm{AgNO}_{3}$ per $\mathrm{SMG}$, (3) $4 \mathrm{mg} \mathrm{mL}^{-1} \mathrm{AgNO}_{3}$ per gum SMG, (4) $3 \mathrm{mg} \mathrm{mL}^{-1} \mathrm{AgNO}_{3}$ per gum SMG, (5) $2 \mathrm{mg} \mathrm{mL}^{-1} \mathrm{AgNO}_{3}$ per gum SMG, (6) $1 \mathrm{mg} \mathrm{mL}^{-1} \mathrm{AgNO}_{3}$ per gum SMG, (7) ampicillin $1 \mathrm{mg} \mathrm{mL}^{-1}$ used as positive control

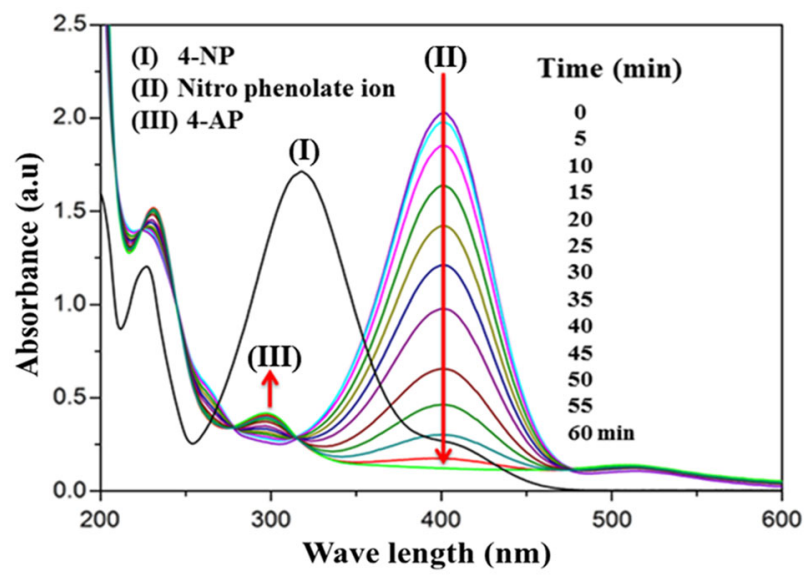

Fig. 7 Successive UV-visible absorption spectra of the reduction of $0.2 \mathrm{mM}$ 4-nitrophenol by $15 \mathrm{mM} \mathrm{NaBH}_{4}$ in the presence of SMGcapped AgNPs as catalyst. The time between two consecutive curves is $5 \mathrm{~min}$

catalytic reduction of 4-NP exclusively yielded 4-AP without any other products or by-products.

In this reduction reaction, the concentration of $\mathrm{NaBH}_{4}$ greatly exceeds that of 4-NP (or catalyst, AgNPs) and the excess $\mathrm{NaBH}_{4}$ increases the $\mathrm{pH}$ of the system, thus retarding the degradation of the $\mathrm{BH}_{4}{ }^{-}$. The liberated hydrogen from the reaction is purged out, thereby checking the aerial oxidation of the reduced product of 4-NP. The metallic nanoparticles initiated catalysis is possible due to efficient transfer of electron from donor $\mathrm{BH}_{4}{ }^{-}$ion to acceptor 4-nitrophenolate ion mediated by AgNPs, thereby reducing the activation energy of the reaction. Since the concentration of borohydride ion added in the system is much higher in comparison with that of 4-NP, the reduction rate can be assumed to be independent of $\mathrm{NaBH}_{4}$ 


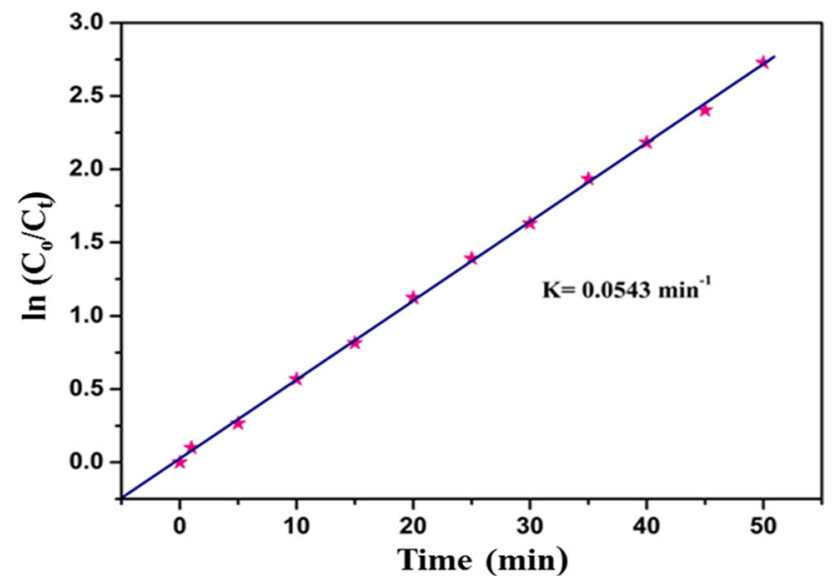

Fig. 8 Plot of $\ln C_{0} / C_{t}$ against time for pseudo-first-order reduction kinetic reaction of nitrophenol to aminophenol in the presence of excess of $\mathrm{NaBH}_{4}(15 \mathrm{mM})$ in aqueous solutions

concentration. Therefore, a pseudo-first-order kinetics could be used to evaluate the kinetic reaction rate of the current catalytic reaction. Figure 8 shows a linear correlation between $\ln \left(C_{0} / C_{t}\right)$ (where $C_{0}$ is the absorbance at the initial time, $C_{t}$ the absorbance at the specific time) and the reaction time at room temperature, indicating that the reaction is of pseudo-first-order. The pseudo-first-order rate constant $(k)$ at room temperature is calculated from the slope $\left(k=0.0543 \mathrm{~min}^{-1}\right)$ for SMG-capped AgNPs.

\section{Conclusion}

In summary, a simple, clean, economically viable, and "green" approach has been established for the synthesis of AgNPs using non-toxic and renewable SMG as a reducing and capping agent without using any harsh, synthetic reducing agents. The greener synthesis of SMG-capped NPs was found to be eco-friendly due to the fact that the reactions involve exudates from renewable plant resources. The designed SMG-capped AgNPs are highly stable, and have shown significant antibacterial activity against both the bacterial strains of E. coli and $S$. aureus. The catalytic ability of the SMG-capped AgNPs to initiate the reduction reactions such as 4-nitrophenol to 4-aminophenol in the presence of $\mathrm{NaBH}_{4}$ certainly draws greater importance due to the cleaner and greener approach. The kinetics of the reaction was found to be of pseudo-first-order with respect to the 4-NP. Owing to the outstanding antibacterial and catalytic properties of functionalized nanoparticles such as SMG-capped AgNPs, these can be a promising and potential candidates in biomedical and pharmaceutical and biosensor applications.

Acknowledgments The authors wish to thank Prof. T. P. Radhakrishna, Center for Nanotechnology, University of Hyderabad, for his help in the TEM analysis of samples.
Conflict of interest The author declares no competing interest.

Open Access This article is distributed under the terms of the Creative Commons Attribution 4.0 International License (http:// creativecommons.org/licenses/by/4.0/), which permits unrestricted use, distribution, and reproduction in any medium, provided you give appropriate credit to the original author(s) and the source, provide a link to the Creative Commons license, and indicate if changes were made.

\section{References}

Ahrland S, Chatt J, Davies NR (1958) The relative affinities of ligand atoms for acceptor molecules and ions. Q Rev Chem Soc $12: 265-276$

Amit Kumar M, Abhishek K, Banerjee UCh (2012) Free radical scavenging and antioxidant activity of silver nanoparticles synthesized from flower extract of Rhododendron dauricum. Nano Biomed Eng 4:118-124

Aruna Jyothi K, Sashidhar RB, Arunachalam J (2010) Gum kondagogu (Cochlospermum gossypium): a template for the green synthesis and stabilization of silver nanoparticles with antibacterial application. Carbohydr Polym 82:670-679

Bose S, Dutta AS (1936) structure of salmalia malabarica gum.II: structure of the degrade gum. J Indian Chem Soc 40:557-561

Bose S, Dutta AS (1963) structure of salmalia malabarica gum.I: nature of sugars present and the structure of aldobiuronic acid. J Indian Chem Soc 40:257-262

Burda C, Chen X, Narayanan R, El-Sayed MA (2005) Chemistry and properties of nanocrystals of different shapes. Chem Rev 105:1025-1102

Chau YF, Yeh HH (2011) A comparative study of solid-silver and silver-shell nanodimers on surface plasmon resonances. J Nanopart Res 13:637-644

Chen X, Schluesener HJ (2008) Nanosilver: a nanoproduct in medical application. Toxicol Lett 176:1-12

Cho KH, Park JE, Osaka T, Park SG (2005) The study of antimicrobial activity and preservative effects of nanosilver ingredient. Electrochim Acta 51:956-960

Devi LB, Mandal B (2013) A Self-assembly of Ag nanoparticles using hydroxypropyl cyclodextrin: synthesis, characterisation and application for the catalytic reduction of $p$-nitro phenol. RSC Adv 3:5238-5253

Dhar S, Murawala P, Shiras A, Pokharkar V, Prasad B (2012) Gellan gum capped silver nanoparticle dispersions and hydrogels: cytotoxicity and in vitro diffusion studies. Nanoscale 4:563-567

El-Rafie MH, Mohamed AA, Shaheen ThI, Hebeish A (2010) Antimicrobial effect of silver nanoparticles produced by fungal process on cotton fabrics. Carbohydr Polym 80:779-782

El-Sayed MA (2001) Some interesting properties of metals confined in time and nanometer space of different shapes acc. Chem Res $34: 257-264$

Faizi S, Zikr-ur-Rehman S, Naz A, Muhammad AV, Dar A, Naqvi S (2012) Bioassay-guided studies on Bombax ceiba leaf extract: isolation of shamimoside, a new antioxidant xanthone C-glucoside. Chem Nat Compd 48:774-779

Feng QL, Wu J, Chen GQ, Cui FZ, Kim TN, Kim JO (2000) A mechanistic study of the antibacterial effect of silver ions on E. coli and Staphylococcus aureus. J Biomed Mater Res 52:662-668

Hatchett DW, Henry S (1996) Electrochemistry of sulfur adlayers on low-index faces of silver. J Phys Chem 100:9854-9859 
Jain V, Verma SK (2012) Pharmacology of Bombax ceiba Linn. Springer Briefs in Pharmacology and Toxicology. doi:10.1007/ 978-3-642-27904-1_4

Jana NR, Peng X (2003) Single-phase and gram-scale routes toward nearly monodisperse au and other noble metal nanocrystals. J Am Chem Soc 125:14280-14281

Jiang LP, Xu S, Zhu JM, Zhang JR, Zhu JJ, Chen HY (2004) Ultrasonic-assisted synthesis of monodisperse single-crystalline silver nanoplates and gold nanorings. Inorg Chem 43:5877-5883

Jones CM, Hoek E (2010) A review of the antibacterial effects of silver nanomaterials and potential implications for human health and the environment. J Nanopart Res 12:1531-1551

Kenneth KY, Wong SOF, Cheung LH, Niu J, Tao C, Ho C-M, Che C-M, Tam PKH (2009) Further evidence of the anti-inflammatory effects of silver nanoparticles. Chem Med Chem 4:1129-1135

Kora AJ, Manjusha R, Arunachalam J (2009) Superior bactericidal activity of SDS capped silver nanoparticles: synthesis and characterization. Mater Sci Eng C 29:2104-2109

Kumar A, Kumar-Vemula P, Ajayan PM, John G (2008) Silvernanoparticle embedded antimicrobial paints based on vegetable oil. Nat Mater 7:236-241

Lee GJ, Shin SI, Kim YC, Oh SG (2004) Preparation of silver nanorods through the control of temperature and $\mathrm{pH}$ of reaction medium. Mater Chem Phys 84:197-204

Lori Rastogi J, Arunachalam J (2011) Sunlight based irradiation strategy for rapid green synthesis of highly stable silver nanoparticles using aqueous garlic (Allium sativum) extract and their antibacterial potential. Mater Chem Phys 129:558-563

Mahapatra SS, Karak N (2008) Silver nanoparticle in hyper branched polyamine: synthesis, characterization and antibacterial activity. Mater Chem Phys 112:1114-1119

Maneerung T, Tokura S, Rujiravanit R (2008) Impregnation of silver nanoparticles into bacterial cellulose for antimicrobial wound dressing. Carbohydr Polym 72:43-51

Pal A, Shah S, Devi S (2009) Microwave-assisted synthesis of silver nanoparticles using ethanol as a reducing agent. Mater Chem Phys 114:530-532

Prabhu S, Poulose EK (2012) Silver nanoparticles: mechanism of antimicrobial action, synthesis, medical applications, and toxicity effects. Int Nano Lett 32:1-10

Qu YQ, Porter R, Shan F, Carter JD, Guo T (2006) Synthesis of tubular gold and silver nanoshells using silica nanowire core templates. Langmuir 22:6367-6374

Raffi M, Hussain F, Bhatti TM, Akhter JI, Hameed A, Hasan MM (2008) Antibacterial characterization of silver nanoparticles against E. coli ATCC-15224. J Mater Sci Technol 24:192-196
Roldan MV, Lucia B, Scaffardi O, de Sanctis N, Pellegri N (2008) Optical properties and extinction spectroscopy to characterize the synthesis of amine capped silver nanoparticles. Mater Chem Phys 112:984-990

Saleem R, Ahmad SI, Ahmad M, Faizi Z, Rehman S, Ali M, Faizi S (2003) Hypotensive activity and toxicology of constituents from Bombax ceiba stem bark. Biol Pharm Bull 26:41-46

Sang WK, Jin HJ, Kabir LYSK, Ji SM, Youn SL (2012) Antifungal effects of silver nanoparticles (AgNPs) against various plant pathogenic fungi. Mycobiology 40:53-58

Sharma VK, Yngard RA, Lin Y (2009) Silver nanoparticles: green synthesis and their antimicrobial activities. Adv Colloid Interface Sci 145:83-96

Shon YS, Cutler E (2004) Aqueous synthesis of alkane thiolatedprotected Ag nanoparticles using Bunte salts. Langmuir 20:6626-6630

Stockman GD, Barrett JF (1983) Structure, function, and assembly of cell walls of gram-positive bacteria. Annu Rev Microbiol 37:501-527

Tagad C, Dugasani S, Aiyer R, Park S, Kulkarni A, Sabharwal S (2013) Green synthesis of silver nanoparticles and their application for the development of optical fiber based hydrogen peroxide sensor. Sens Actuator B Chem 183:144-149

Tang S, Vongehr S, Meng X (2010) Carbon spheres with controllable silver nanoparticle doping. J Phys Chem C 114:977-982

Tiwari DK, Behari J, Sen P (2008) Time and dose-dependent antimicrobial potential of $\mathrm{Ag}$ nanoparticles synthesized by topdown approach. Curr Sci 95:647-655

Xu X, Yang Q, Wang Y, Yu H, Chen X, Jing X (2006) Biodegradable electrospun poly (L-lactide) fibers containing antibacterial silver nanoparticles. Eur Polym J 42:2081-2087

Xu W, Jin W, Lin L, Zhang C, Li Z, Li Y, Song R, Li B (2014) Green synthesis of xanthan conformation-based silver nano particles: antibacterial and catalytic application. Carbohydr Polym 101:961-967

Yin H, Yamamoto T, Wada Y, Yanagid S (2004) Large-scale and size-controlled synthesis of silver nanoparticles under microwave irradiation. Mater Chem Phys 83:66-70

Yoksan R, Chirachanchai S (2009) Silver nanoparticles dispersing in chitosan solution: preparation by $\gamma$-ray irradiation and their antimicrobial activities. Mater Chem Phys 115:296-302

Yu D, Yam VWW (2004) Controlled synthesis of mono disperse silver nanocubes in water. J Am Chem Soc 126:13200-13201 